----مجلة علوم الرافدين، المجلد 27، العدد 4/ عدد خاص بالمؤتمر العلمي الثالث لعلوم الحياة، ص 418-429، 2018--

تأثير استخدام ثنائي أوكسيد التيتانيوم النانوي في السيطرة على الخمج الثانوي

لطفيلي المشوكات الحبيبية Echinococcus granulosus داخل الجسم الحي

$$
\text { رعد عبدالحميد عبدالغني }
$$

Email: Najah_sobhi@yahoo.com $\quad$ Email: raadalgany@gmail.com

$$
\text { (أستلم 4/ } 7 \text { / 2018 ؛ قُبل 2018/11/1) }
$$

تضمنت الدراسة تأثير استخدام المركب ثنائي أوكسيد التنتانيوم النانوي (TiO2) بحجمين مختلفين 10 و 250 نانومينز وبالتركيز 3 ملغم/مل لكل حجم للفترتين شهر وشهرين، إذ تم تجربتها على الخمج الثانوي في الجرذان سلالةة Rattus norvegicus بأي مادة والسيطرة الموجبة المجرعة بالرؤيسات الأولية فقط من أجل بيان تأثثر المزيج داخل الجسم الحي، إذ تبين حدوث التين إتزال

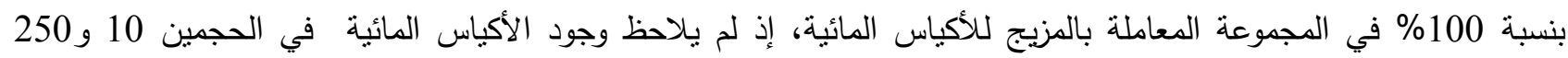
نانوميتر من علامات مرضية تتراوح بين تجمعات بؤرية لخلايا التهابية بسيطة والتهاب مزمن معتدل في المجموعة المعاملة بحجم 10 نانوميتر

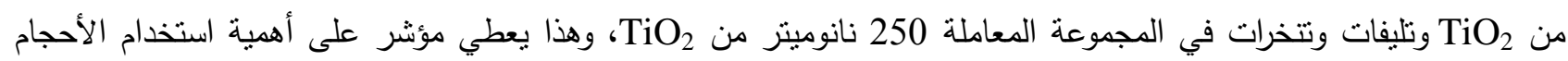
الصغيرة من $\mathrm{TiO}_{2}$ النانوي كمضاد لنمو الأكياس المائية الثنانوية.

الكلمات الدالة: الأكياس المائية، ثنائي أوكسيد التيتانيوم النانوي، المشوكات الحبيية.

\title{
The Effect of Using Nanoparticles Titanum Dioxied to Control of Secondary Infection of Echinococcus granulosus In vivo
}

\author{
Najah S. Naeef \\ Department of Biology /College of Sciences/University of Mosul \\ Raad A. Abd-Algany
}

ABSTRACT

Current study covered the effect of titanium dioxide nanoparticles $\left(\mathrm{TiO}_{2}\right)$ size 10 and 250 $\mathrm{nm}$, using $3 \mathrm{mg} / \mathrm{ml}$ for month and two months for each size. $\mathrm{TiO}_{2}$ used against secondary infection in rats strain Rattus norvegicus, where administrated by 2000 protoscolices treated with each size of $\mathrm{TiO}_{2}$. Above treated animals compared with other left free with any treatments as a negative control and other animals just treated with protoscolices as a positive control. The effect of protoscolices and $\mathrm{TiO}_{2}$ mixture were revealed a reduction in rate of infection by $100 \%$ for each size 10 and 250 $\mathrm{nm} \mathrm{TiO}_{2}$ and for each period month and two months. Histological changes in each of liver and intestine have studied. Several pathological changes including focal aggregation of inflammatory cells and mild chronic inflammation for $\mathrm{TiO}_{2}$ size $10 \mathrm{~nm}$ were noted, while fibrosis and nicrosis were noted at $250 \mathrm{~nm}$ of $\mathrm{TiO}_{2}$. These results gave important sigs that small size of $\mathrm{TiO}_{2}$ may be work as a good antigrowth for developing secondary hydatidosis.

Keywords: Titanium dioxide nanoparticles $\left(\mathrm{TiO}_{2}\right)$, hydatid cyst. 


\section{المقدمة}

يُعد مرض الأكياس المائية أحد الأمراض الطفيلية والذي ينتقل من أكلات اللحوم إلى الإنسان والحيوانات أكلات

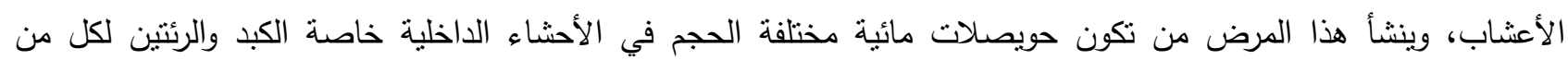
الإنسان والحيوان، لذا يعرف هذا المرض باسم الأكياس المائية أو المرض العدري وتتوقف خطورة المرض على فلى عدد وحجم ومكان تلك الأكياس (McMnus et al., 1986). تُعد الأكياس (الحويصلات) المائية الطور اليرقي لدودة المشوكات الحبيبية Echinococcus granulosus

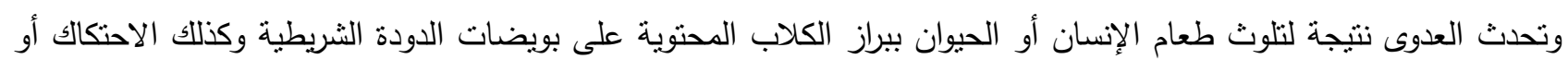

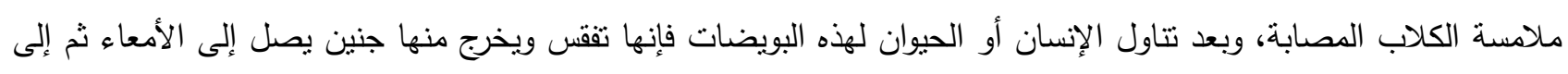
الدم لينتقل إلى الكبد والرئتين والأماكن المختلفة في الجسم مكونة ما يعرف بالحويصلة المائية التي يتراوح قطرها ما بين (1سم (Thomson et al., 1995; Parija, 2004). على الرغم من الجهود المبذولة في علاج الإصابة بالطفيليات، خاصة الجيارديا، المشنقات الدموية، التريبانوسوما، الملاريا، اللشمانيا، حمى الضنك، التهاب الدماغ الياباني وداء الخيطيات، تنتمر الإصابة وخاصة في الأقطار الفقيرة ذات الدخل المحدود (Santos et al., 2010; Elmi et al., 2013; Allahverdiyev et al., 2011). بما أن مقاومة الأدوية تؤدي إلى إعطاء جرعات عالية من المضادات الحيوية مما يؤدي غالبا إلى توليد سمية لا نطاق وتطوير مضادات حيوية جديدة ومكلفة، لذلك لجأ حديثا إلى بدائل المضادات الحيوية وهي استكثاف المواد النانوية وهذه الجسيمات النانوية تمتلك العديد من المزايا المميزة منها خفض التكاليف مقارنة ببقية العلاجات وكذلك إلى استقرارها لتخزين طويل

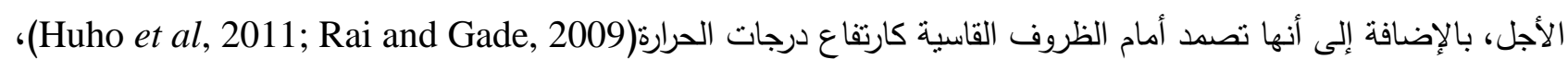
يتأكد لنا أن المواد النانوية هي واحدة من المواد التي تظهر خصائص جديدة على أساس خصائص محددة مثل الحجم والتوزيع

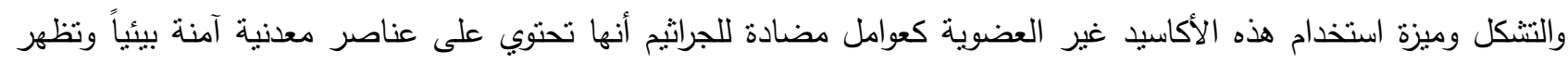
نشاط قوي حتى عندما نستعمل بكميات صغيرة (Stoimenov et al., 2002; Brayner et al., 2006) وقد أوضحت البحوث وجود آليات قتل الكائنات الحية تعمل عليها الجزئيات النانوية دنها قابليتها على الربط بقوة بين الكبريت والفسفور والتي تكون

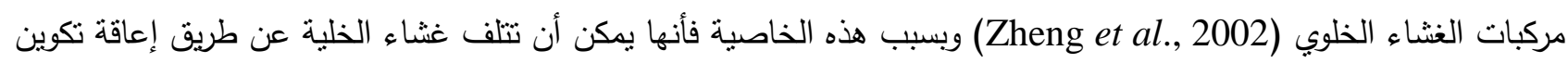

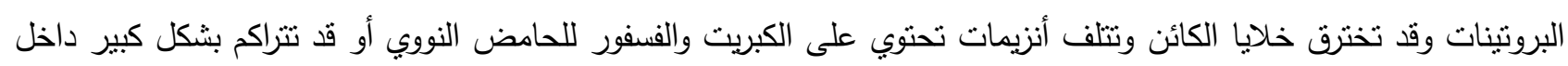
المايتوكوندريا وتضعف وظيفتها عن طريق الإجهاد التأكسدي (Xia et al., 2006; Asharani et al., 2009)، لذا هدفت فئت الدراسة الحالية إلى استخدام المواد النانوية كمضاد لنمو الأكياس المائية الثانوية.

\section{المواد وطرائق العمل}

تحديد تأثير ثنائي أوكسيد التيتانيوم النانوي TiO2Nps على حيوية الطقيلي: لاختبار الفعالية التثبيطية لدقائق 7 تراكيز وهي (0.05، 0.1، 0.2، 0.5، 1.5، 1.5، 3) ملغم/ مل لكل حجم من أحجام ثنائي أوكسيد التيتانيوم النانوي

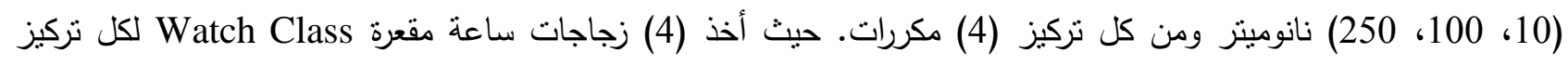
ووضع في كل زجاجة 1000 رؤيس وأضيف بعد ذلك حجم 1 مل من كل تركيز من تراكيز ثنائي أوكسيد التيتانيوم النانوي المراد معرفة تأثيرها على حيوية الطفيلي مقارنة مع مجموعة السيطرة. 
تم إجراء الفحص لكل تجربة لمعرفة عدد الرؤيسات الحية المنبقية والنسبة المئوية للتثبيط، إذ فحصت العينات المعاملة بالتراكيز المختلفة من ثنائي أوكسيد التيتانيوم النانوي مقارنة مع مجموعة السيطرة خلال فترات زمنية مختلفة تضمنت (5، 10، 30، 60) دقيقة. كررت كل تجربة (3) مرات للحصول على نتائج دقيقة.

\section{تصميم التجرية داخل جسم الكائن الحي In vivo:} في هذه الدراسة تم استخدام ثثائي أوكسيد التيتانيوم النانوي TiO بحجم 10 و 250 نانوميتز والتي تم الحصول عليها من شركة M. KImpex corp Canda الكندية، إذ نم استخدام تركيز 3 ملغم/مل في كل التجربة. إذ قسمت الجرذان الذكور البالغة Rattus norvegicus

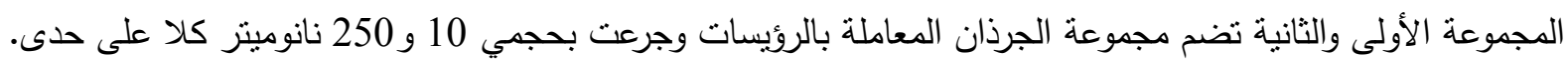
المجموعة الثالثة تضم مجموعة الجرذان المعاملة بالرؤيسات فقط وعدت كمجموعة سبطرة موجبة والتي يتم الحصول عليها من مجزرة أربيل. المجموعة الرابعة تضم مجموعة الجرذان الغير معاملة وعدت كمجموعة سيطرة سالبة، حيث نم تجريع الجرذان للمجموعة الأولى والثانية بحجم 1 مل من المحلول الحاوي على 1000 رؤيس، مع

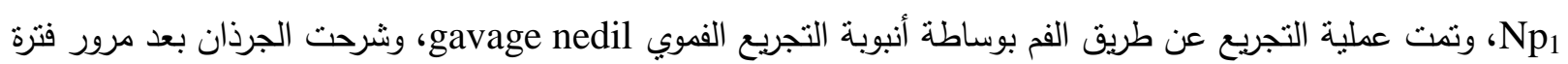

$$
\text { 30، } 60 \text { يوم على التجريع. }
$$

تشريح الجرذان:

تم تشريح الجرذان بعد تخديرها بالايثز وتثييتها للتحري عن وجود الأكياس المائية وانتشارها على الأعضاء الداخلية بمساعدة العدسة المكبرة، وبعدها تم استئصال الأجزاء المصابة من الكبد وجزء من الأمعاء الدقيقة ووضعها في الفورمالين بتركيز .\%10

لدراسة التغيرات النسجية لكل من الكبد والأمعاء في الجرذان المعاملة بثنائي أوكسيد التنتانيوم النانوي الرؤيسات الأولية لمعرفة التأثنرات النسجية. وأختير الكبد لكونه أكثر الأعضاء التي تتعرض للأذى بسبب وظيفته في تأييض

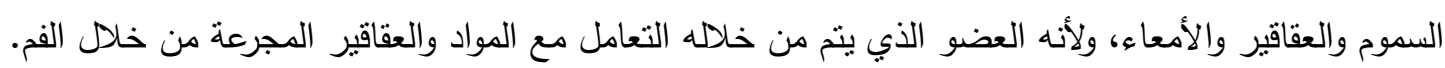

تحضير الشرائح المجهرية:

نم أخذ قطع صغيرة من الكبد والأمعاء الدقيقة من موقع الإصابة ووضعت في قناني صغيرة حاوية على المحلول المثبت فورمالين لمدة (24-72) ساعة. بعد ذلك نم غسل القطع النسيجية بالماء الجاري للتخلص من المحلول المثبت الزائد لمدة 15

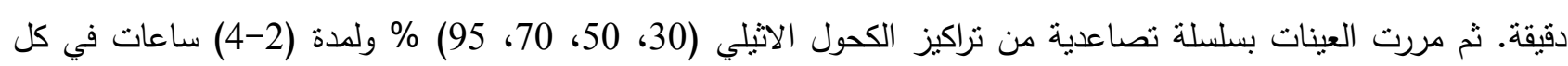
تركيز لإزالة الماء من الأنسجة. مررت العينات بثلاث مراحل من الزايلين Xylene وبمعدل ساعتين في كل مرحلة لغرض تتقية

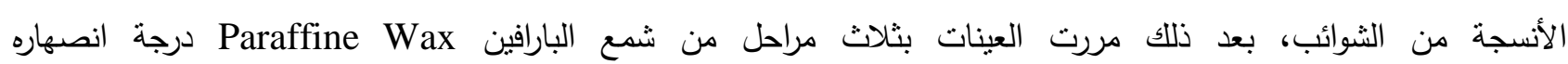
(56-60)م لمدة ساعتين في كل مرحلة بدرجة 60 م لغرض التشريب. طمرت العينات بوضع الثمع في قوالب حديدية على شكل فئل حرف L ثم تركت في مكان بارد. شذبت قوالب الشمع Trimming الحاوية على المقاطع تثذيبا دقيقا وثبتت على جهاز المشراح الدوار Microtome وقطعت لغرض الحصول على شرائح نسجية بسمك (5-6) مايكروميتر حملت الأشرطة المقطوعة بوساطة

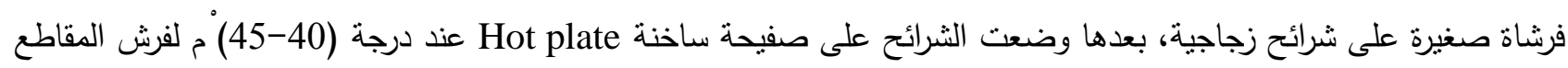

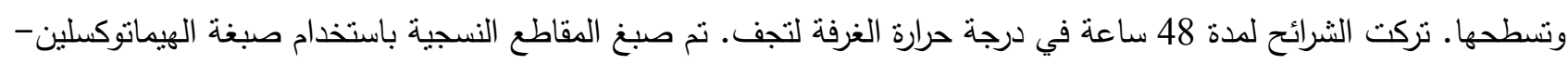
ايوسين حسب طريقة (1975 (Dancroft وحملت بوساطة دسترين بلاسترز - زايلين (D. P. X) ووضع الغطاء الزجاجي. 


\section{النتائج}

إذ يبين الثكل (1) مقطع عرضي في نسيج كبد أحد جرذان السيطرة السالبة، نظهر فيه الخلايا الكبدية بحجمها الطبيعي والجيبانيات Sinusoids كانت طبيعية، كذلك وجود خلايا كفر مرتبة بأعداد وأحجام طبيعية أيضا، مع ظهور الوريد المركزي

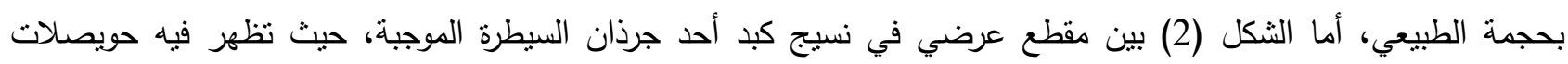

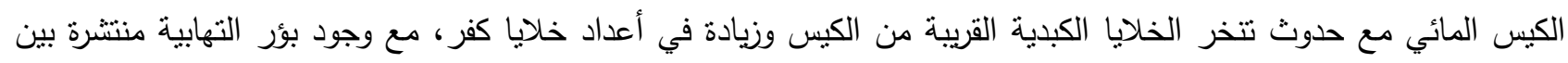
خلايا الكبد، وكذلك ظهور تكيس الكيس المائي في الكبد، وهذا دليل على تغلب الطفيلي على الوسائل الدفاعية للمضيف وإفراز المستضدات التي تعمل على تثبيط الآلية المناعية للمضيف. يبين الثكلين (3) و (4) مقاطع في نسيج أكباد جرذان معاملة بالرؤيسات الأولية مع فئل 3 ملغم/مل وللفترات شهر وشهرين، حيث لوحظ من خلاله ظهور تجمع بؤري بسيط لخلايا التهابية حول الوريد المركزي، مع في في

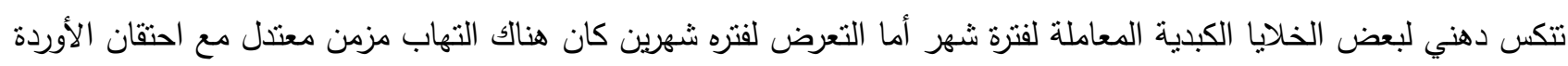

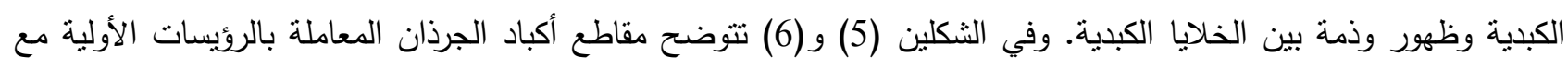
بحجم 250 نانوميتر احتقان خفيف في الأوردة البوابية المركزية والجيوب الكبدية مع تجمع أكبر وكثيف لخلايا إلتهابية حول الأوردة الكبدية المعاملة لفترة شهر ـ أما في فترة التعرض لشهرين ظهر هناك نخر التردة موضعي للنسيج الكبدي واحتقان شديد للأوردة الكبدية. أما بالنسبة لنسيج الأمعاء فالثكل (7) يوضح مقطع للزغابات في منطقة اللفائفي لجرذ غير معامل (سيطرة سالبة)، يظهر فيه

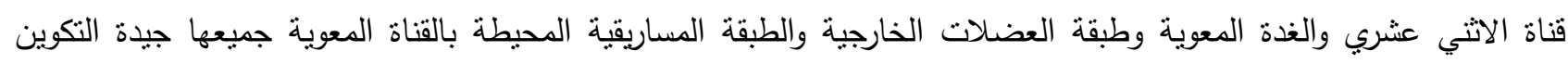

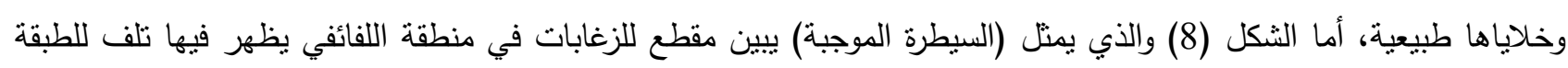
الطلائية بعد مرور شهرين من المعاملة بالرؤيسات الأولية، وكذلك يبين الشكلين (9) و (10) مقاطع في أمعاء جرذان معاملة

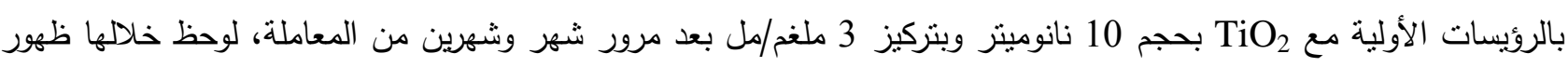
نسيج حبيبي في الطبقة الأصلية مع وجود المايوسين في التجويف المعوي المعاملة لفترة الثهر ، أما بعد مرور فترة الثهرين

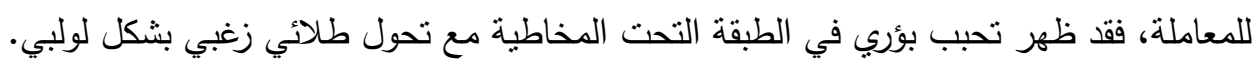

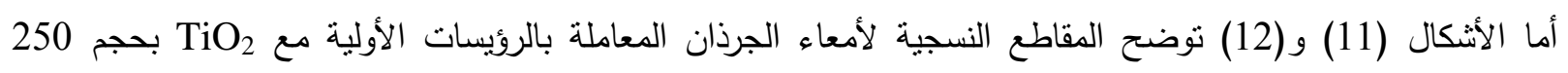
نانوميتز وبتركيز 3 ملغم/مل، إذ ظهر ضمور في القناة الهضمية بشكل عام وقلة عدد الزغابات وتحول في النسيج المخاطي

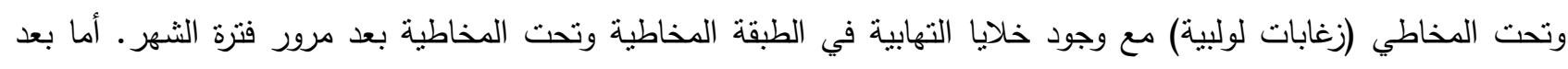
مرور فترة الثهرين من المعاملة، فقد كانت التأثثرات بشكل تحول في الأنسجة الغدية المعوية إلى نسيج لمفاوي حبيبي مع ظهور منطقة ليفية في الوسط وتحبب بؤري للزغابة مع مظهر لولبي للزغابات ( تشوه distortion).

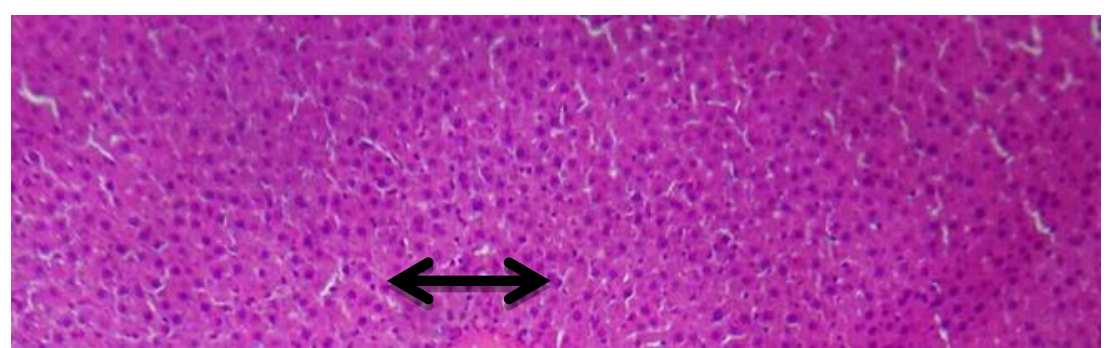


الثكل 1: مقطع في كبد جرذ غير معامل (سيطرة سالبة) يظهر فيه النسيج الكبدي بصورة طبيبعة حيث

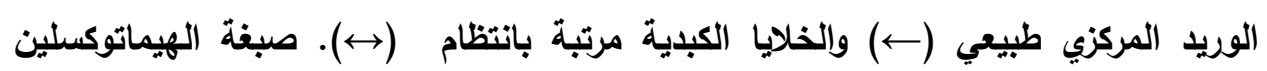
والايوسين تحت قوة تكبير 230X.

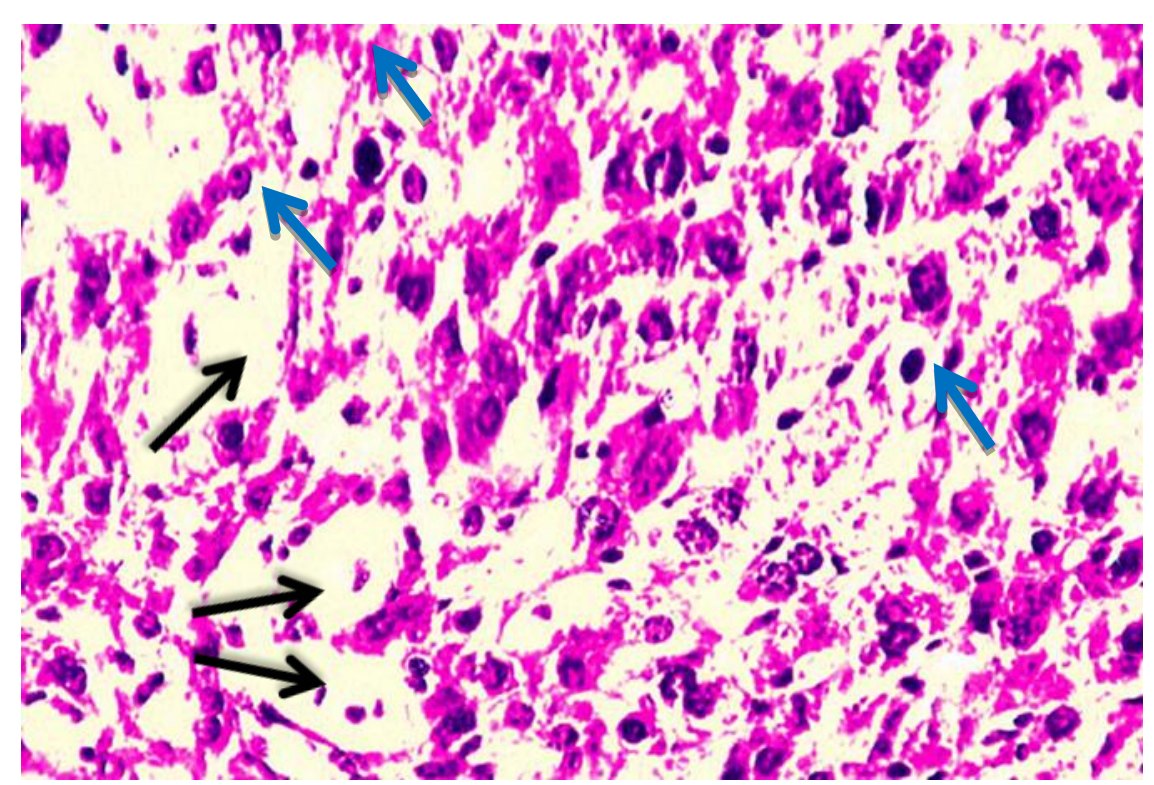

الثكل 2: مقطع في كبل جرذ مصاب بعد مرور شهرين من المعاملة بالروئيسات الاولية تظهر فيه حويصلات

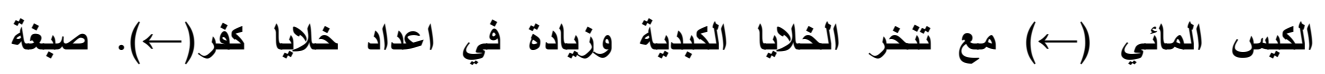

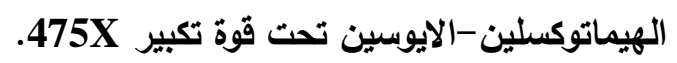




$$
\text { رعد عبدالحميد عبدالغني و نجاح صبحي نايف }
$$

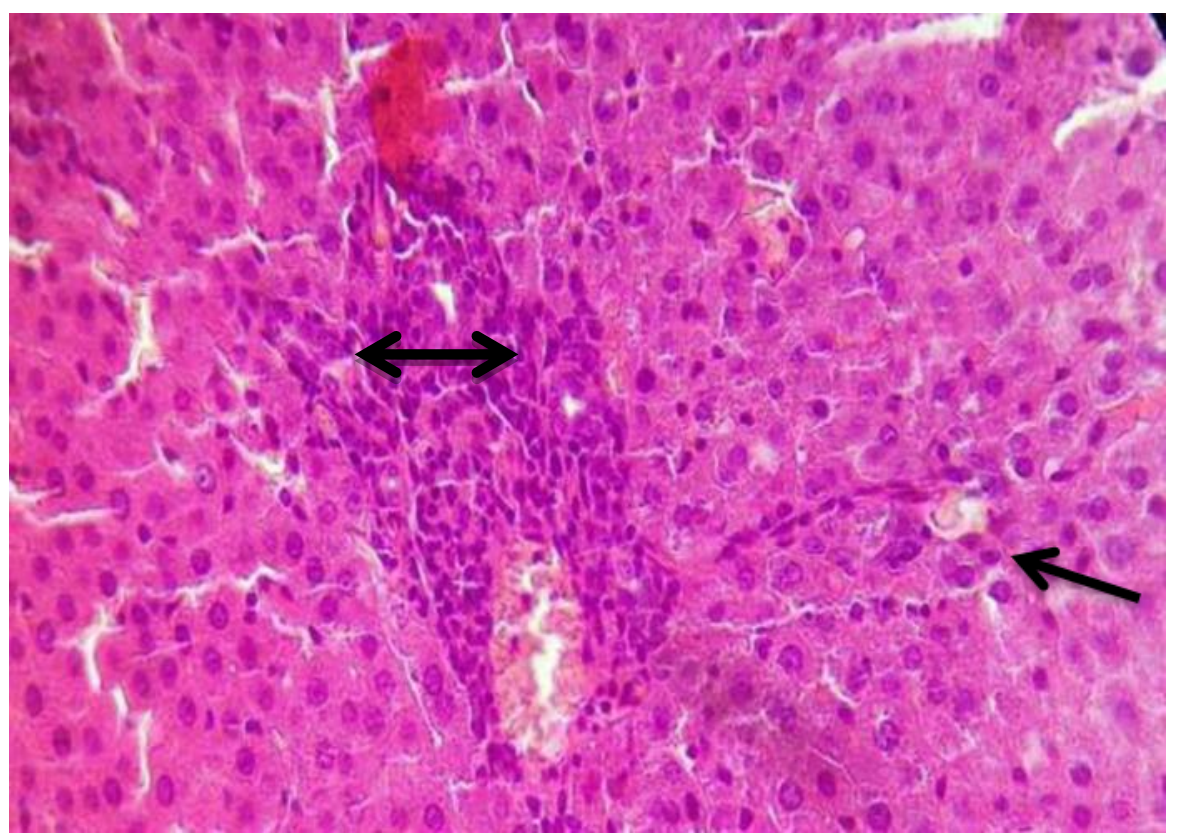

الشكل 3: مقطع في كبد جرذ معامل بالروئيسات الاولية مـ TiO2 بحجم 10 نانوميتر ويتركيز 3 ملغم/مل ولفترة شهر يظهر فيه باية تجمع بؤري بسيط لخلايا التهابية حول الوريد المركزي (؟) وتنكس دهني لبعض الخلايا الكبدية(↔). صبغة الهيماتوكسلين-الايوسين تحت قوة تكبير 400X.

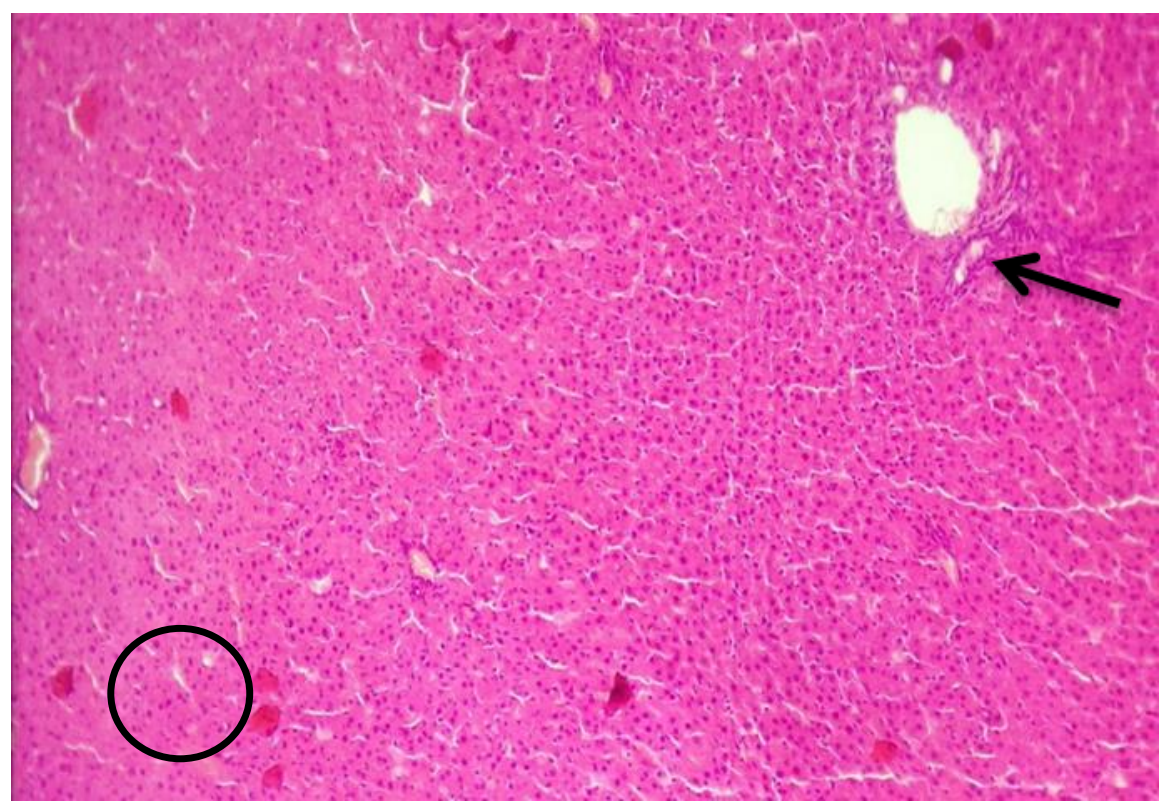

الثكل 4: مقطع في كبا جرذ معامل بالرويسات الاولية مع TiO2 بحجم 10 نانوميتر ويتركيز 3 ملغم/مل

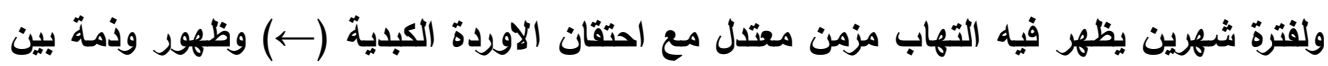

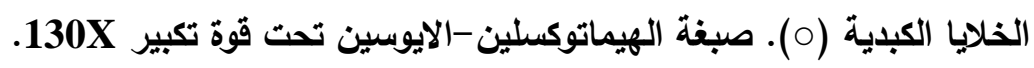




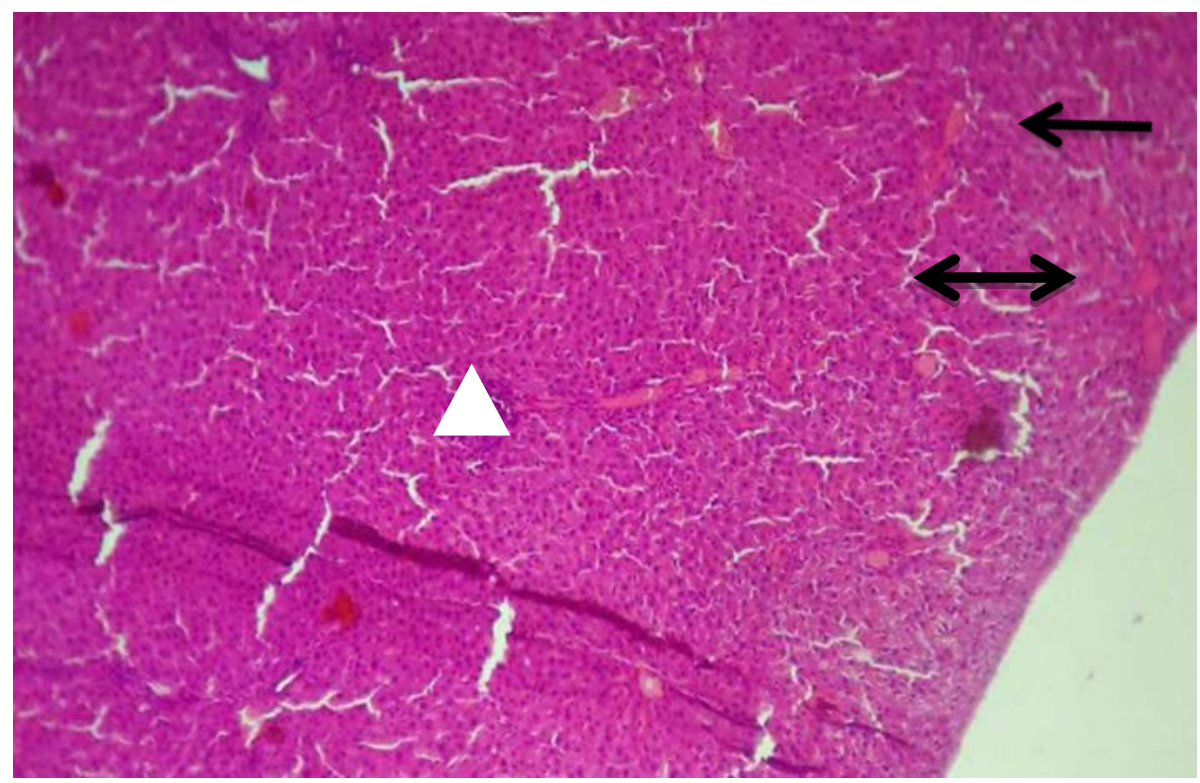

الشكل 5: مقطع في كبد جرذ معامل بالروئيسات الأولية مع TiO2 بحجم 250 نانوميتر ويتركيز 3 ملفم/مل

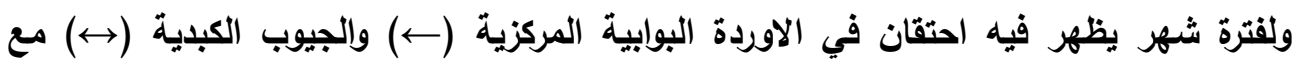

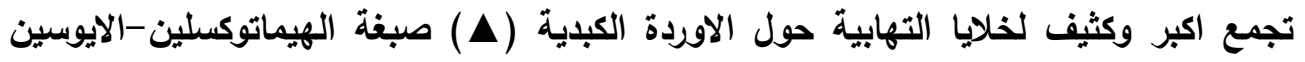
تحت قوة تكبير 170X.

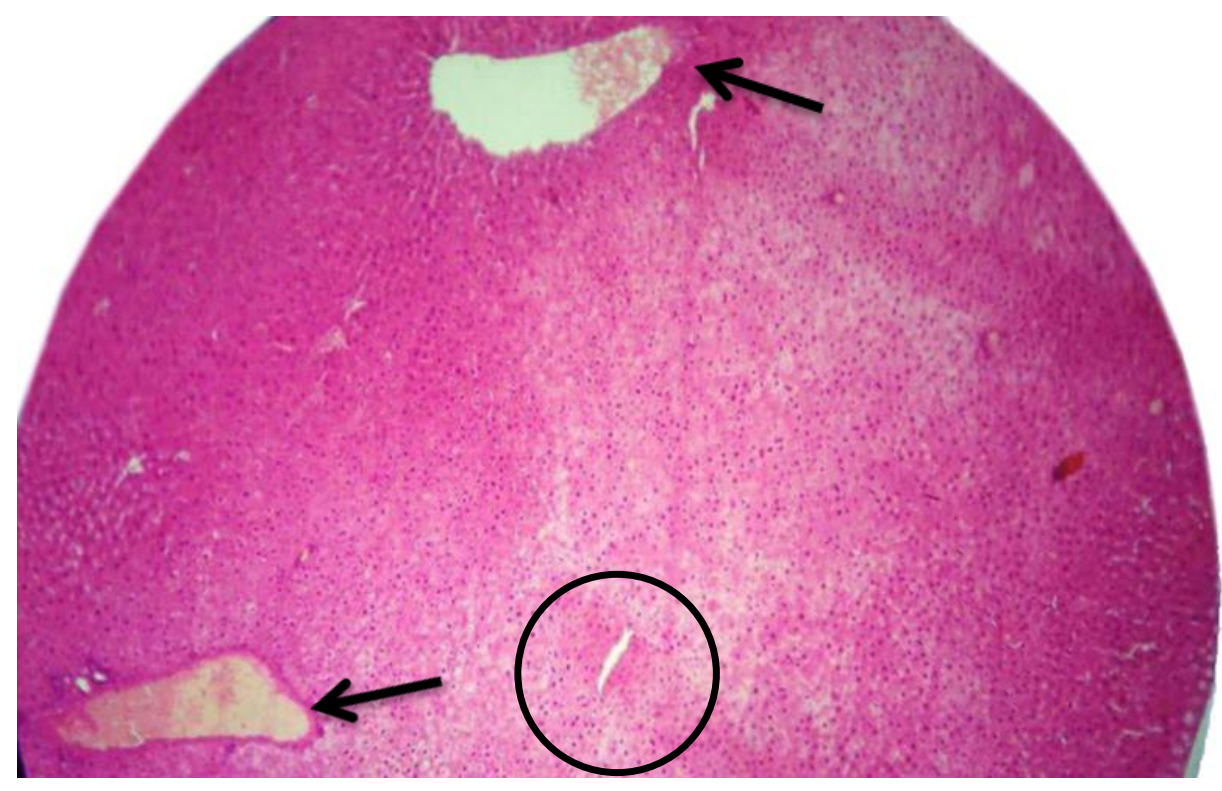

الثكل 6: مقطع في كبا جرذ معامل بالروئيسات الاولية مع TiO2 بحجم 250 نانوميتر ويتركيز 3 ملفم/مل

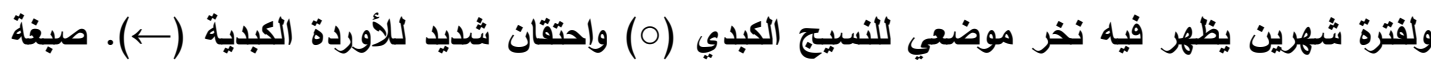
الهيماتوكسلين -الايوسين تحت قوة تكبير 150X. 


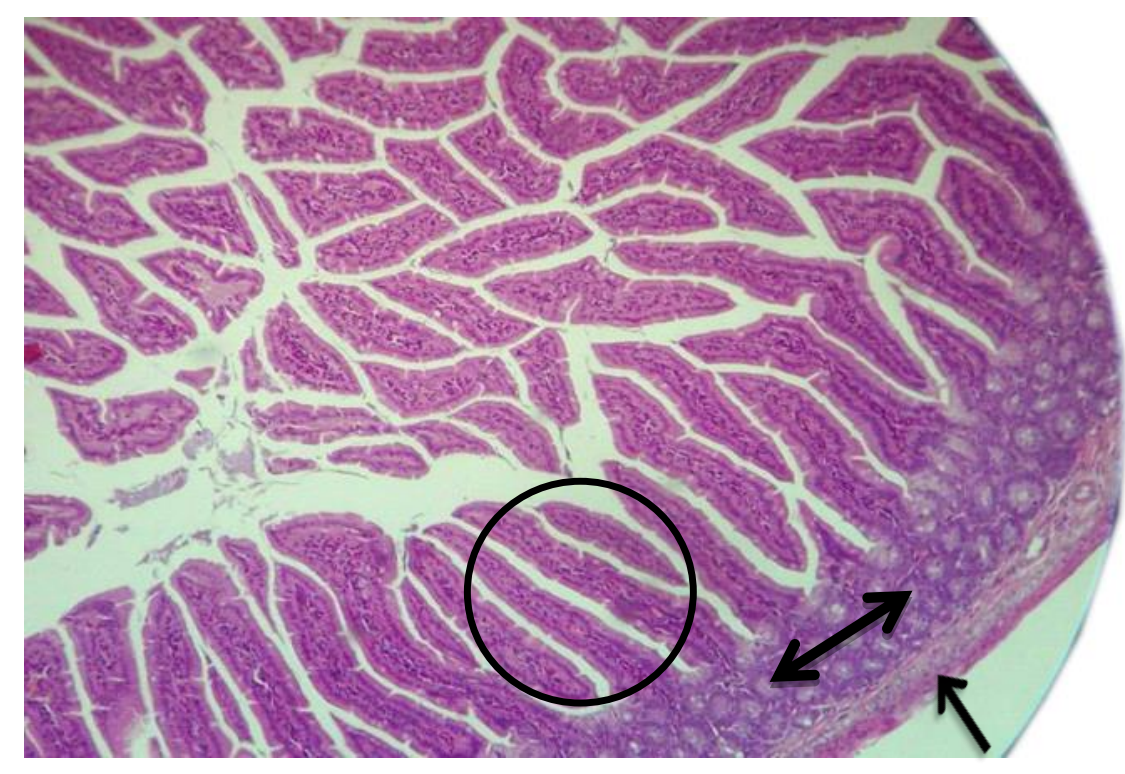

الشكل 7: مقطع في أمعاء جرذ غير معامل (سيطرة سالبة) يظهر فيه قناة الاثني عشري جيدة التكوين حيث

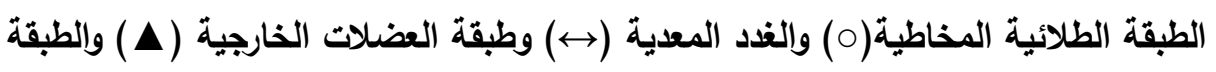

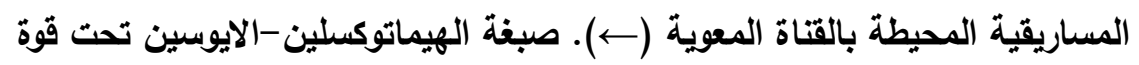
تكبير $200 \mathrm{X}$

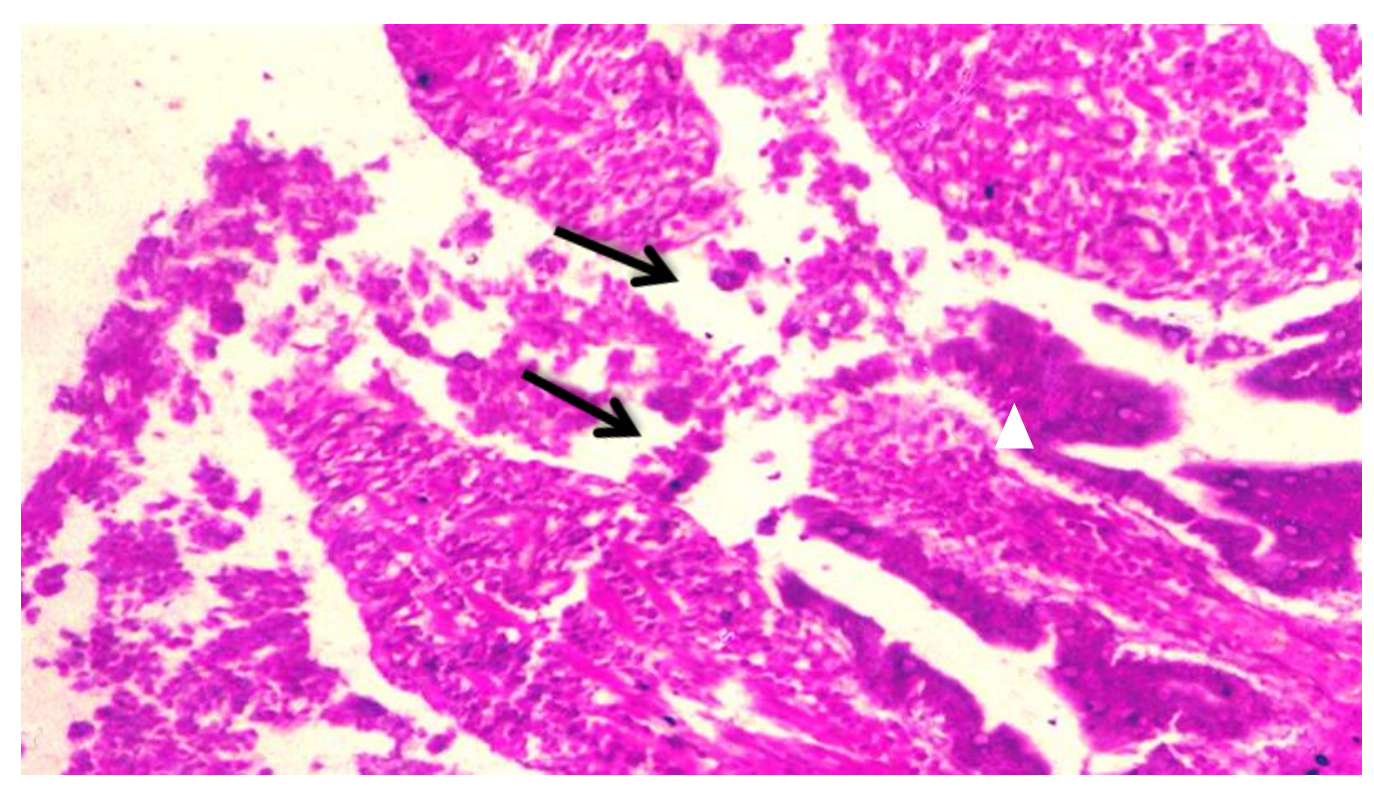

الشكل 8: مقطع لزغابات في منطقة اللفائفي جرذ مصاب بعد مرور شهرين من المعاملة بالروئيسات الأولية

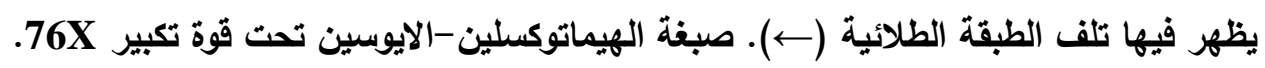




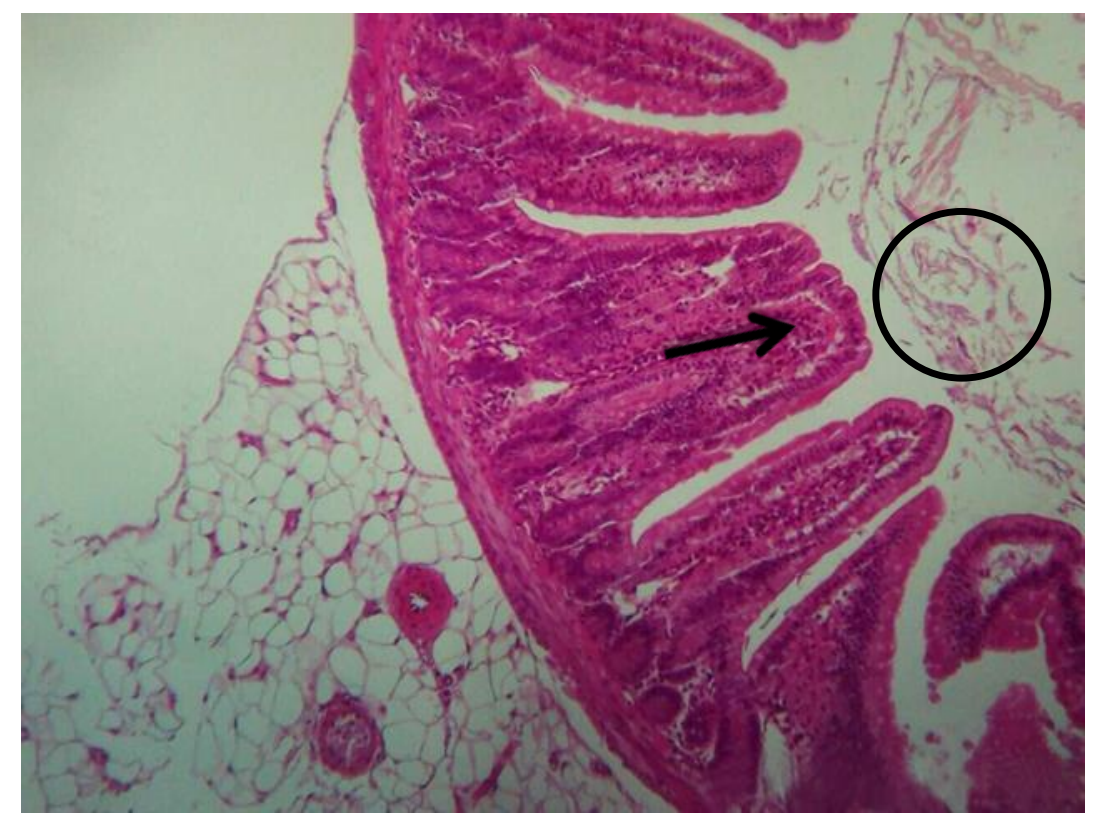

الشكل 9 : مقطع في أمعاء جرذ معامل بالروئيسات الاولية مع 10 TiO بحجم 10 نانوميتر

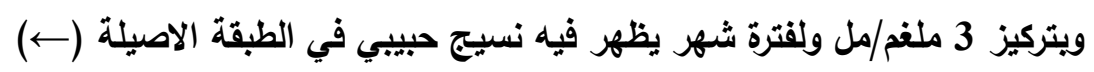

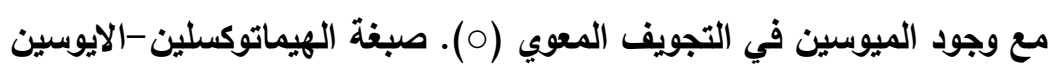
تحت قوة تكبير 300X.

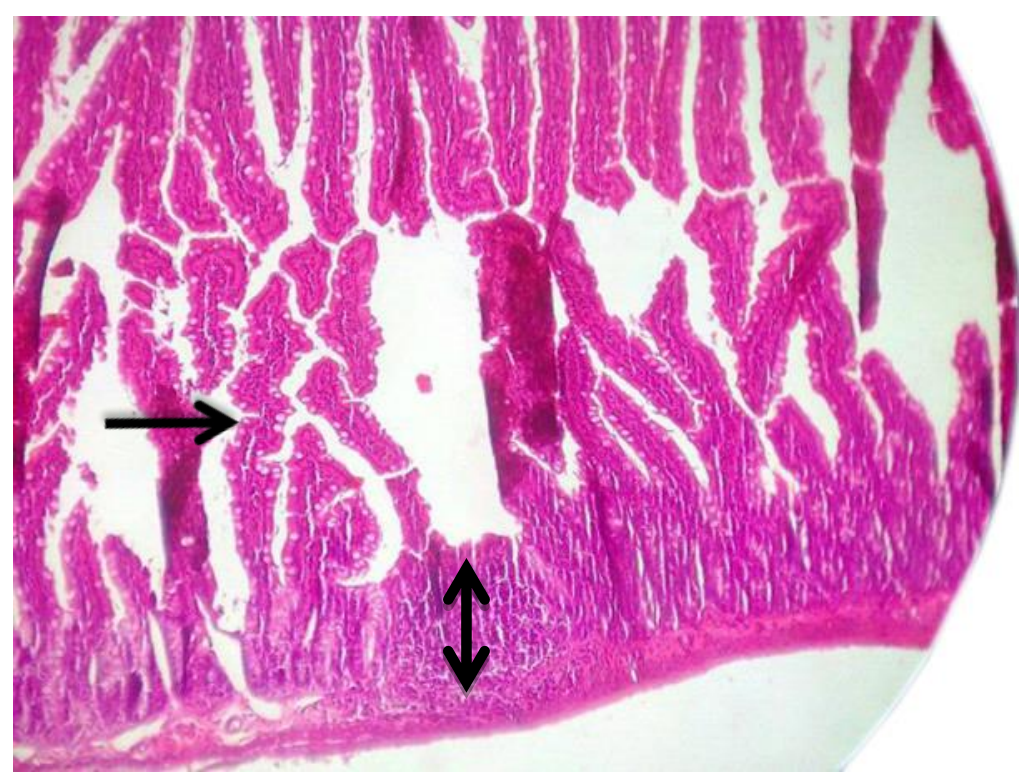

الثكل 10: مقطع في أمعاء جرذ معامل بالرؤيسات الاولية مع TiO

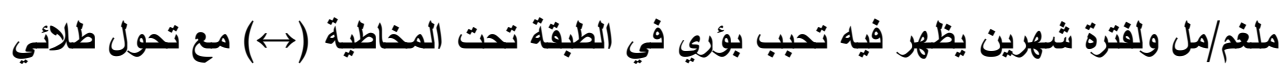

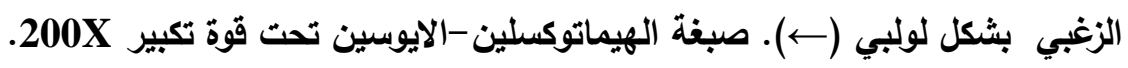




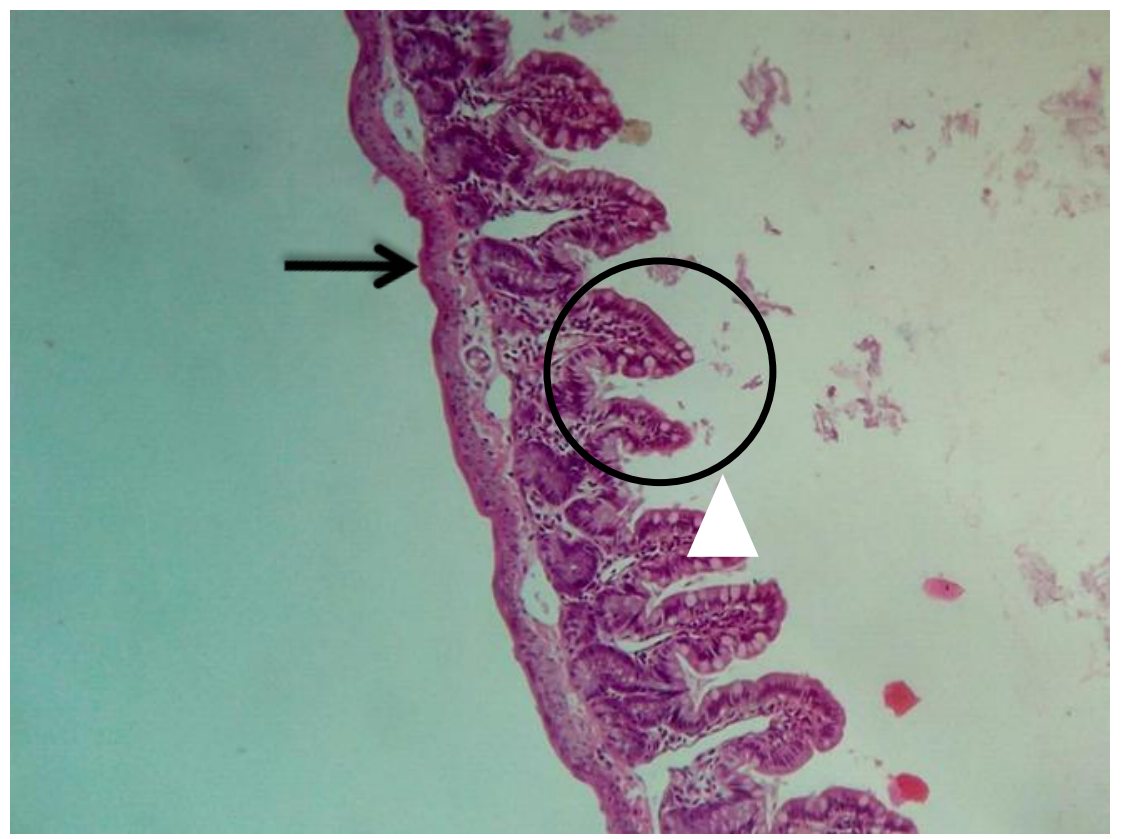

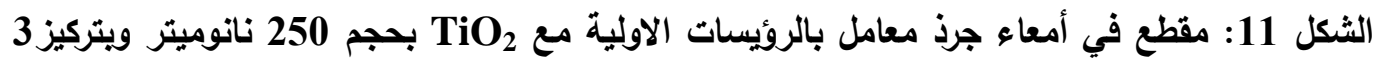

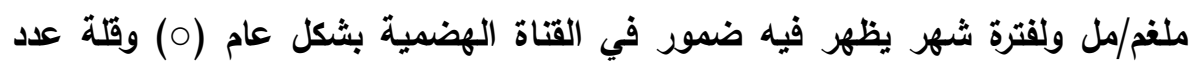

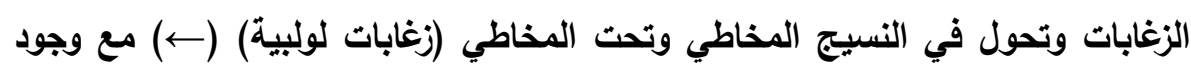

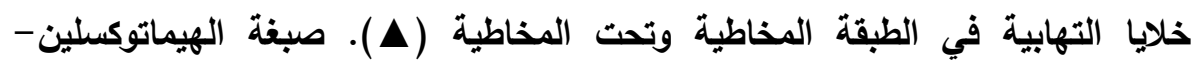
الايوسين تحت قوة تكبير

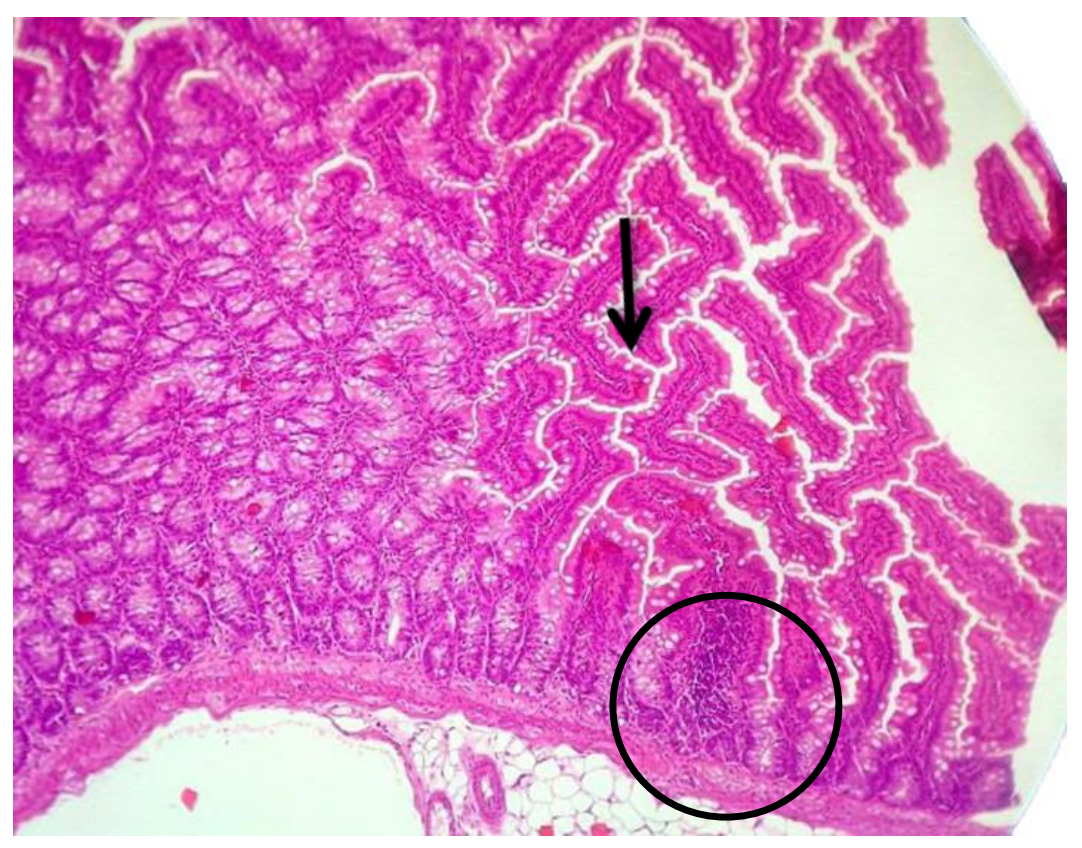

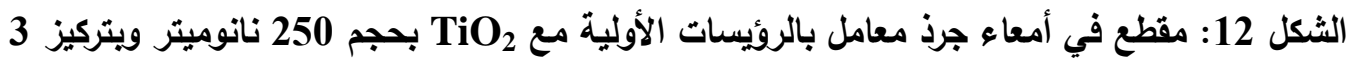

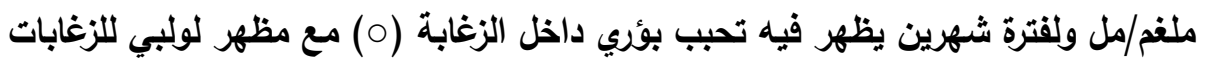

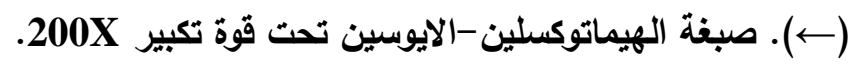




\section{المناقشة}

يتضح من النتائج التي توصلت إليها الدراسة الحالية في الثكلين (3) و (6) أن نأثنير TiO الثانوية بتركيز 3 ملغم/مل وبالحجم 10 نانوميتز كان أكثز ملائمة من استخدام الحجم 250 نانوميتز ، وذلك لتأثيره المتوازن والخفيف على الأنسجة المدروسة، حيث تراوحت ثأثثراته بين التجمعات البؤرية البسيطة للخلايا الإلتهابية والإلتهابات المزمنة المعتلة.

بينما استخدام الحجم 250 نانوميتر سبب في احتقانات شديدة للأوردة الكبدية مع تجمعات كبيرة وكثيفة للخلايا الالتهابية حول الأوردة الكبدية وهذا يتفق مع ما جاء به (Abdulla, 2017) عند استخدامه

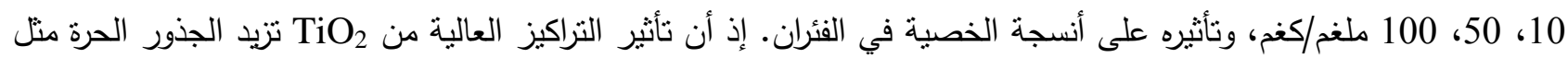

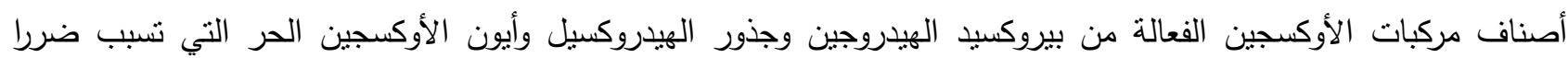

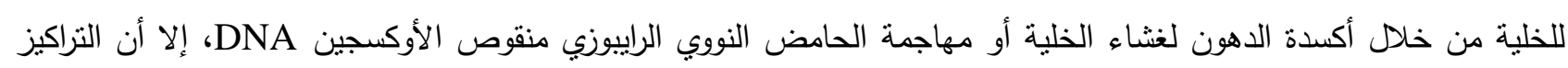

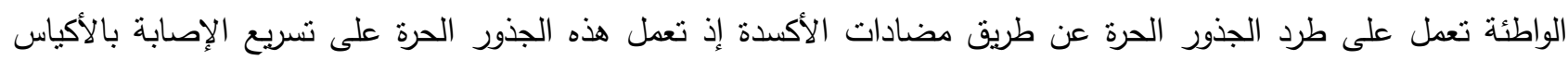
المائية.

من خلال ما ذكر أعلاه كوصف للمقاطع النسجية في الثكلين (7) إلى (12) كان الثأثير للتيتانيوم على الرؤيسات الأولية قاتلا بحيث لم تظهر أي نمو لأكياس مائية ثانوية في تلك المقاطع بعد مرور فترة شهر وشهرين على المعاملة بثنائي

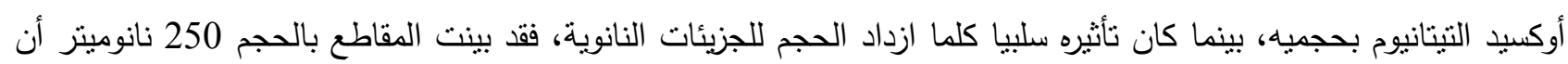

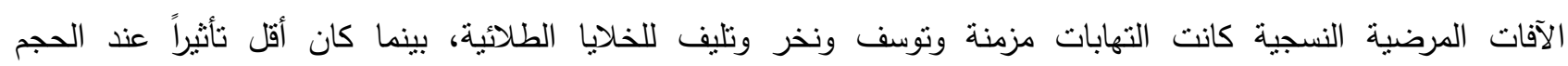
10 نانوميتز متمثلا بظهور تحبب بؤري في الطبقة تحت المخاطية، تفسير ذلك أن

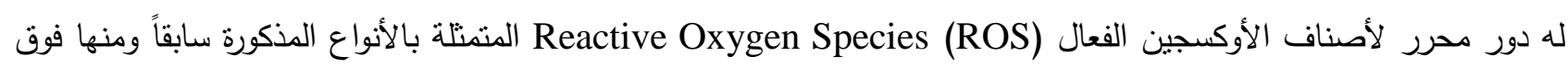

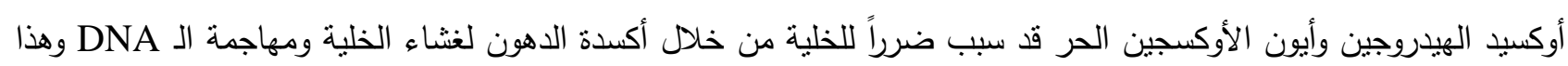

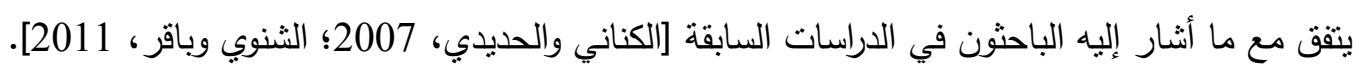

\section{الاستتتاجات والتوصيات}

عند مقارنة تأثيرات أحجام TiO النانوي داخل الجسم الحي (نسجي) أظهر الحجم 250 نانو تأثثرات سلبية على الأنسجة المدروسة أكثر من الحجم الأخر TiO

توصي الدراسة إجراء دراسات أخرى على عدة تراكيز منخفضة من غير المؤثر سلبياً على الأنسجة. ودراسة نأثثر TiO

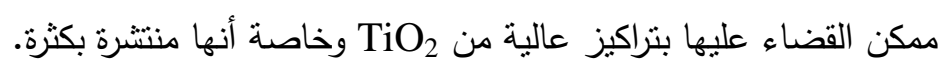

\section{المصادر العربية}

الكناني، انتصار رحيم؛ الحديدي، هناء خليل (2007). دراسة مرضية نسيجية على دور الرؤيسات الثانوية للمشوكة الحبييية في

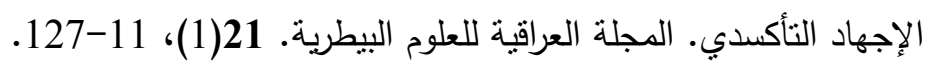

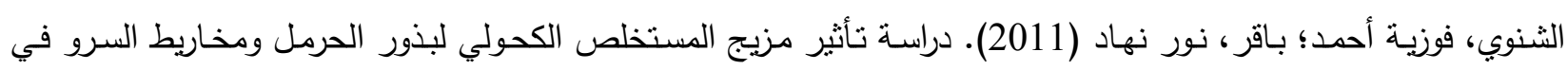

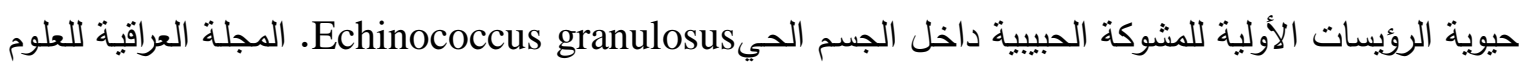




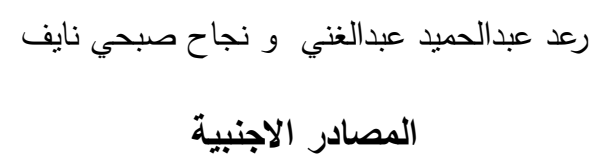

Abdulla, I.T. (2017). Histological effects of titanium dioxied nanoparticles size $10 \mathrm{~nm}$ in mice testes. Department of Biology, College of Science, Faculty of Science, University of Zakho, Kurdistan region, Iraq. 5(2), 158-161.

Allahverdiyev, A.M.; Abamor, E.S.; Bagirova, E.S.; Bagirova, M.; Ustundag, C.B.; Kaya, C.; Kaya, F. (2011). Antileishmanial effect of silver nanoparticles and their enhanced antiparasitic activity under ultraviolet light. Int. J. Nanomedicine. 6, 2705-14.

Asharani, P.V., Low Kah Mun, G.; Hande, MP.; Valiyaveettil S. (2009). Cytotoxicity and genotoxicity of silver nanoparticles in human cells. ACS Nano.; 3(2), 279-290.

Bancroft, J.D. (1975). "Histological Techniques". $2^{\text {nd }}$ ed. Butterworth London and Boston.

Brayner, R.; Ferrari-lliou R.; Brivois, N.; Djediat, S.; Benedetti, M.F.; Fievet, F. (2006): Toxicological Effect of ZnO Nanoparticles Based on Bacteria," Nano Lett. 6:866.

Elmi, T., Gholami, S., Fakhar, M.; Azizi, F. (2013). A review on the use of nanoparticles in the treatment of parasitic infections. J. Mazand Uni Med Sci., 23,127-34.

Huh, A. J.; Kwon, Y.J. (2011). Nanoantibiotics A for treating infectious diseases using nanomat antibiotics resistant era. J. controlled Relea bing nanomaterials. (156), 128-145.

McManus, D.P.; Smyth, J.D. (1986). Hydatid concepts in epidemiology and speciation. Parasitol. Today., 2, 163-168

Parija, S.(2004). Hydatid fluid as a clinical specimen for the aetiological diagnosis of asuspected hydatid cyst. J. Parasit. Dis., 28(2), 64-68.

Rai, M.; Yadav, A.; Gade, A. (2009). Silver nanoparticles as a new generation of antimicrobials. Biotechnol. Adv. 27,76-83.

Santos-Magalhaes, N.S.; Mosqueira, V.C. (2010). Nanotechnology applied to the treatment of malaria. Adv Drug Deliv Rev.; 62(4-5), 560-75. 67. Said De, ElSamad LM, Gohar YM. Validity of silver, chitosan, and curcumin nanoparticles as anti-Giardia agents. Parasitol Res. 111(2), 545-54.

Stoimenov, P.K.; Klinger, R.L.; Marchin, G.L.; Klabunde, K.J. (2002). Metal oxide nanoparticles as bacterividal agents, Langmuir. 18, 6679.

Thompson, R.C.A.; Lymbery, AJ.; Gonstantine, C.C. (1995). Variation in E. granulosus towards ataxonomic revision in Switzerland. Int. J. Parasitol., 14, 283-291.

Xia, T.; Kovochich, M.; Brant, J. (2006). Comparison of the abilities of ambient and manufactured nanoparticles to induce cellular toxicity according to an oxidative stress paradigm. Nano Lett. 6(8), 1794-1807.

Zheng, J.; Wu, X.; Wang, M.; Ran, D.; Xu, W.; Yang, J. (2008). Study on the interaction between silver nanoparticles and nucleic acids in the presence of cetyltrimethyl ammonium bromide and is analytical application. Talanta. 74 (4),526-532. 